\title{
Effect of the miR-96-5p inhibitor and mimic on the migration and invasion of the SW480-7 colorectal cancer cell line
}

\author{
PEI YUAN HE ${ }^{1}$, WAI KIEN YIP ${ }^{2}$, MOHD FAISAL JABAR ${ }^{3}$, NORHAFIZAH MOHTARRUDIN ${ }^{2}$, \\ NORAINI MOHD DUSA ${ }^{4}$ and HENG FONG SEOW ${ }^{2}$ \\ ${ }^{1}$ Department of Gastroenterology, Affiliated Hospital of Chengde Medical University, Chengde, Hebei 067000, P.R. China; \\ ${ }^{2}$ Department of Pathology, ${ }^{3}$ Department of Surgery, Faculty of Medicine and Health Sciences, Universiti Putra Malaysia, \\ Serdang, Selangor 43400; ${ }^{4}$ Department of Pathology, Hospital Kuala Lumpur Jalan Pahang, Kuala Lumpur 50586, Malaysia
}

Received February 21, 2017; Accepted November 2, 2018

DOI: $10.3892 / 01.2019 .10492$

\begin{abstract}
The objectives of the present study were to identify the aberrant expression of microRNA (miRNA) in colorectal carcinoma (CRC) tissues from published miRNA profiling studies and to investigate the effects of the identified miRNA inhibitor and mimic miR-96-5p on CRC cell migration and invasion. The altered expression of the regulators of cytoskeleton mRNA in miR-96-5p inhibitor-transfected cells was determined. The miR-96-5p expression level in five CRC cell lines, HCT11, CaCo2, HT29, SW480 and SW620, and 26 archived paraffin-embedded CRC tissues were also investigated by reverse-transcriptase quantitative polymerase chain reaction (RT-qPCR). Cell viability in response to the miR-96-5p inhibitor and mimic transfections was determined by an MTT assay. A Matrigel invasion assay was conducted to select the invasive subpopulation designated SW480-7, by using the parental cell line SW480. The effects of miR-96-5p mimic- or inhibitor-transfected SW480-7 cells on cell migration and invasion were evaluated using the Transwell and Matrigel assays, and the change in expression of the regulators of cytoskeleton mRNAs was identified by Cytoskeleton Regulators $\mathrm{RT}^{2}$-Profiler PCR array followed by validation with RT-qPCR. CRC tissues exhibited a significant increase in miR-96-5p expression, compared with their matched normal adjacent tissues, indicating an oncogenic role for miR-96-5p.
\end{abstract}

Correspondence to: Dr Pei Yuan He, Department of Gastroenterology, Affiliated Hospital of Chengde Medical University, 36 Nanyingzi Street, Chengde, Hebei 067000, P.R. China

E-mail: peiyuanhe@163.com

Abbreviations: CRC, colorectal cancer; PET, polyethylene terephthalate; DMSO, dimethyl sulfoxide; PI, propidium iodide; MYLK2, myosin light chain kinase 2; MLC, myosin regulatory light chain; MYLK, myosin light chain kinase; MLCP, myosin light chain phosphatase; ECM, extracellular matrix; VMP1, vacuole membrane protein 1

Key words: microRNA-96-5p, colorectal cancer, Matrigel, migration, invasion, cytoskeleton
The results demonstrated that the miR-96-5p inhibitor decreased the migration of SW480-7 cells, but had no effect on invasion. This may be due to the promotion of cell invasion by Matrigel, which counteracts the blockade of cell invasion by the miR-96-5p inhibitor. The miR-96-5p mimic enhanced SW480-7 cell migration and invasion, as expected. It was determined that there was a $>2.5$ fold increase in the expression of genes involved in cytoskeleton regulation, myosin light chain kinase 2, pleckstrin homology like domain family $\mathrm{B}$ member 2, cyclin A1, IQ motif containing GTPase activating protein 2, Brain-specific angiogenesisinhibitor 1-associated protein 2 and microtubule-actin crosslinking factor 1 , in miR-96-5p inhibitor-transfected cells, indicating that they are negative regulators of cell migration. In conclusion, the miR-96-5p inhibitor blocked cell migration but not invasion, and the latter may be due to the counteraction of Matrigel, which has been demonstrated to stimulate cell invasion.

\section{Introduction}

Colorectal cancer (CRC) is a common malignancy and a main cause of cancer-associated mortalities globally $(1,2)$. Although significant progress has been achieved in understanding the pathogenesis of CRC, current treatment regimens remain with a low 5-year survival rate, particularly for patients diagnosed with a late stage of the disease. The majority of patients with CRC are diagnosed with an advanced stage of CRC, and thus further improvements in the treatment of these patients are of the utmost importance. Cytoskeleton regulation is a key mechanism that drives invasiveness and metastasis in the majority of carcinoma cases (3). Targeting driver genes may be the most successful strategy for treating patients with malignancy and to increase their rate of survival (4); therefore, further studies are required to identify novel therapeutic markers for CRC.

MicroRNAs (miRNAs) are endogenous, small non-coding RNA molecules that regulate the expression of target mRNA at a post-transcriptional level by binding to complementary sites within the 3'-untranslated region (5). It is now known that $\sim 60 \%$ of protein-coding genes are regulated by miRNAs (5) and are involved in a number of processes, involving proliferation, migration, invasion, metastasis, angiogenesis and cytoskeleton disruption (6-9). Recently, several hundred differentially 
expressed miRNAs have been identified by multiple miRNA profiling studies using high-throughput technologies, such as microarray and next generation sequencing, and reported to serve a role in a number of cellular processes, such as miR-200 suppressing CRC migration and miR-106b promoting metastasis (10); however, the mechanisms driving miRNAs in regulating CRC progression remain unclear. Identification of aberrant miRNA expression is the starting point in numerous studies for investigating the influences of miRNAs in CRC. In the present study, one miRNA was identified, miR-96-5p. miR-96-5p has been demonstrated to serve a crucial role in the tumor progression of a number of carcinoma types, including pancreatic carcinoma (11), prostate cancer (12) and hepatocellular carcinoma (13); however, its underlying mechanism in carcinogenesis and progression in CRC remains unknown. Therefore, the aim of the present study was to investigate the role of miR-96-5p in in cell migration and invasion through in vitro studies, and identify which regulatory cytoskeleton mRNA expression are altered in miR-96-5p-inhibitor and mimic-transfected cells.

\section{Materials and methods}

Selection of candidate miRNAs. A PubMed (https://www. ncbi.nlm.nih.gov/) search was conducted on CRC miRNA expression profiling studies published between January 2006 and December 2013. Only studies comparing miRNA expression of CRC tissues with apparently normal adjacent tissues were considered. Intersection analysis was performed using the Venn Diagram software (https://www.venndiagram.net), available online (14). Candidate colon cancer-associated miRNAs were selected according to the following criteria: i) The differentially expressed miRNA was reported in at least two independent studies; ii) these upregulated or downregulated miRNAs were grouped accordingly from independent studies.

Tissue samples and detection of miR-96-5p. A total of 26 archived paraffin-embedded CRC specimens and paired apparently normal adjacent tissues collected between January 2010 and December 2011 were provided by Kuala Lumpur Hospital, Malaysia. Ethics approval was obtained from the National Medical Ethics Board (approval no. NMRR-12-435-11565). The demographic and clinicopathological data of 26 patients, from which the CRC tissues were obtained, are detailed in Table I. The resected colon tissues were histologically observed by hematoxylin and eosin staining,briefly, (6 $\mu \mathrm{m}$ thickness) paraffin slice $60^{\circ} \mathrm{C}$ dried in an oven for $1 \mathrm{~h}$ then conventional xylene, ethanol dewaxing to water, hematoxylin staining for $3 \mathrm{~min}$, flushed with running water to remove residual colour, eosin staining for $30 \mathrm{sec}$, following $90 \%$ ethanol $30 \mathrm{sec}$, $95 \%$ ethanol $30 \mathrm{sec}$, $100 \%$ ethanol $30 \mathrm{sec}$ twice, finally xylene fixed $30 \mathrm{sec}$, neutral gum sealed at room temperature, observed by Olympus reverse microscope (Olympus Corporation, Tokyo, Japan). Sections of $4 \mu \mathrm{m}$ thickness of CRC tumor tissue $v s$. normal adjacent tissue as viewed under the microscope were manually cut from a tissue wax block, mounted onto glass slides followed by deparaffinization, miRNA extraction was performed with the miRNeasy FFPE kit (cat. no. 217504; Qiagen GmbH,
Hilden Germany), according to manufacturer's protocols. cDNA was synthesized through reverse-transcription using the Universal cDNA synthesis kit (Exiqon; Qiagen), according to manufacturer's protocols. miR-96-5p (cat. no. 204417) and U6 (cat. no. 203907) primers were purchased from Exiqon (Qiagen). Due to Locked Nucleic Acid technology was used in the primer synthesis and is covered by patents owned by Exiqon (Qiagen), the sequences of the primers were not provided. Quantitative polymerase chain reaction (qPCR) was conducted with a Mastercycler EP realplex 4 (Eppendorf, Hamburg, Germany) using the SYBR ${ }^{\circledR}$ Green master mix Universal RT kit (Exiqon; Qiagen). qPCR parameters were set as follows: $10 \mathrm{~min}$ at $95^{\circ} \mathrm{C}, 40$ amplification cycles of $10 \mathrm{sec}$ at $95^{\circ} \mathrm{C}$, and annealing and extension for $1 \mathrm{~min}$ at $60^{\circ} \mathrm{C}$. Each sample was run in triplicate. U6 was used as the reference gene and the relative expression was calculated using the standard curve method (15).

Cell culture and transfection. The human CRC cell lines HCT116, Caco2, HT29, SW480 and SW620 were purchased from American Type Culture Collection (Manassas, VA, USA). All of the five cell lines were maintained in RPMI-1640 medium supplemented with $10 \%$ fetal bovine serum (FBS) (Gibco; Thermo Fisher Scientific, Inc., Waltham, MA, USA), $100 \mathrm{IU} / \mathrm{ml}$ penicillin and $100 \mathrm{mg} / \mathrm{ml}$ streptomycin, and incubated at $37^{\circ} \mathrm{C}$ in a humidified chamber containing $5 \% \mathrm{CO}_{2}$.

The miR-96-5p inhibitor, miRNA inhibitor negative control oligos, miR-96-5p mimic and miRNA mimic negative control oligos were purchased from Exiqon (Qiagen) and Cell Death small interfering RNA (siRNA: siRNA-6 (cat. no. si00287448), siRNA-7(cat. no. i00287455), which was used as positive control, was purchased from Qiagen. HCT116 cells $\left(2.1 \times 10^{4} /\right.$ well $)$, SW620 cells $\left(5.5 \times 10^{4} /\right.$ well $)$ and SW480 cells $\left(5.5 \times 10^{4} /\right.$ well) were plated into 24 -well plates. HCT116 cells and SW620 cells were cultured in $400 \mu \mathrm{l}$ RPMI-1640 medium containing 10\% FBS, and SW480 cells were cultured in $500 \mu 1$ RPMI-1640 medium supplemented with $10 \% \mathrm{FBS}$ and penicillin and streptomycin for $24 \mathrm{~h}$ prior to transfection at $37^{\circ} \mathrm{C}$ in a $5 \% \mathrm{CO}_{2}$ incubator. HCT116 cells and SW620 cells were transfected with Lipofectamine ${ }^{\circledR} 2000$ (Invitrogen; Thermo Fisher Scientific, Inc.), and SW480 cells were transfected with HiPerFect (Qiagen), according to manufacturer's protocols. The corresponding transfection conditions are described in Table II. Cells were transferred into Transwell inserts for cell migration assay and cell invasion assay $48 \mathrm{~h}$ after transfection.

Reverse-transcription- $q P C R(R T-q P C R)$. For detection of miR-96-5p expression in CRC cell lines, miRNAs were extracted using the miRNeasy Micro kit (Qiagen). The total RNA was diluted to $500 \mathrm{ng} / \mu \mathrm{l}$ with nuclease free water. The nuclease-free micro-centrifuge tube included $2 \mu \mathrm{l}$ total RNA, $1 \mu \mathrm{l}$ enzyme mix, $2 \mu 1$ reaction buffer and $3 \mu \mathrm{l}$ nuclease-free water. All reagents were mixed and voted gently and finally incubated at $42^{\circ} \mathrm{C}$ for $60 \mathrm{~min}$ to synthesize first-strand cDNA. Then, the nuclease-free tube was heated at $95^{\circ} \mathrm{C}$ for $5 \mathrm{~min}$ to inactivate the reverse transcriptase prior to cooling on ice for 5 min. Real-time PCR components mix included 2X SYBR Select Master Mix $5 \mu$, forward and reverse primer $0.25 \mu \mathrm{l}$ each, cDNA template $1 \mu \mathrm{l}$ and $3.5 \mu \mathrm{l}$ RNase-free water. The 
Table I. Clinical and pathological characteristics of patients included in the present study.

Clinicopathological parameters Number of patients $(n=26)$

\begin{tabular}{lr} 
Sex & \\
Male & 16 \\
Female & 10 \\
Age at diagnosis (years) & \\
$\leq 60$ & 21 \\
$>60$ & \\
Race & 12 \\
Chinese & 10 \\
Malay & 2 \\
Indian & \\
Stage at diagnosis (56) & 10 \\
I & 8 \\
II & 8 \\
III & \\
Tumor site & 14 \\
Left colon & 4 \\
Right colon & 8 \\
Rectum & \\
\hline
\end{tabular}

Table II. Optimal transfection conditions.

\begin{tabular}{lrc}
\hline Cell line & Complex & Total volume $(\mu 1)$ \\
\hline HCT116 & $0.75 \mu 1 \mathrm{LF}+5 \mu 1$ miRNA & 100 \\
SW620 & $0.75 \mu 1 \mathrm{LF}+5 \mu 1$ miRNA & 100 \\
SW480 & $6 \mu 1 \mathrm{HF}+6 \mu 1$ miRNA & 100 \\
\hline
\end{tabular}

LF, Lipofectamine 2000; HF, HiPerFect; miRNA, microRNA. miRNA refers to the miR-96-5p inhibitor or mimic.

thermocycling conditions were as follows: $95^{\circ} \mathrm{C}$ for $2 \mathrm{~min}$, 40 cycles at $95^{\circ} \mathrm{C}$ for $15 \mathrm{sec}, 60^{\circ} \mathrm{C}$ for $15 \mathrm{sec}$ and $72^{\circ} \mathrm{C}$ for $60 \mathrm{sec}$. PCR reactions were performed in duplicate and analyzed by standard curves to assess the amplification specificity.

MTT assay. HCT116 cells $\left(2.5 \times 10^{3} /\right.$ well $)$, SW620 cells $\left(8.4 \times 10^{3} /\right.$ well $)$ and SW480 cells $\left(8.4 \times 10^{3} /\right.$ well $)$ were plated in 96-well plates and transfected with miR-96-5p inhibitor or mimics $96 \mathrm{~h}$ prior to the MTT assay according to the previously described protocol. MTT solution $(10 \mu \mathrm{l})$ was added into each well and the cells were incubated with MTT for $4 \mathrm{~h}$ at $37^{\circ} \mathrm{C}$ in the dark. The RPMI-1640 was replaced with $100 \mu 1$ dimethylsulfoxide (Amresco, LLC, Solon, OH, USA). The absorbance at $570 \mathrm{~nm}$ was measured with a spectrophotometric microtiter plate reader (Dynex Technologies, Inc., Chantilly, VA, USA). The same experiment was repeated three times and each experiment was performed in triplicate. The cell viability values were expressed as a percentage of the control condition, which was considered as $100 \%$ cell viability.
Transwell assay for cell migration and invasion. The in vitro cell invasion and migration assays were conducted utilizing Transwell inserts (Falcon ${ }^{\circledR}$; BD Biosciences, Franklin Lakes, NJ, USA). The bottom of the Transwell insert is made of a polyethylene terephthalate (PET) membrane with $8 \mu \mathrm{m}$ pores, allowing cells to pass through. Cell migration was considered positive when cells were capable of moving from one site to another, whilst for cell invasion, positive results were when cells invaded through the basement membrane into an adjacent tissue or vasculature; therefore, the PET membrane of Transwell insert used in cell invasion experiment was coated with $5 \mathrm{mg} / \mathrm{ml}$ Matrigel Matrix (BD Biosciences). The Transwell inserts were placed into 24-well cell culture plates separating the wells into upper and lower chambers. An invasive subpopulation called SW480-7 was derived from SW480 cell line in vitro, briefly, parental SW480 cells were subjected to the Transwell Matrigel invasion assay, the cells that invaded to the bottom of the membrane were detached with $0.25 \%$ trypsin and cultured in a new cell culture flask filled with RPMI-1640 medium. The cells were established via 7 sequential passages through Matrigel-coated Transwells. SW480-7 cells were transfected $48 \mathrm{~h}$ prior to the Transwell assay as performed by the previously outlined protocol. Transfected cells were resuspended in $200 \mu \mathrm{l}$ serum-free medium (RPMI-1640) and then seeded into the upper chambers of Matrigel coated membranes (for cell invasion assay) or uncoated membranes (for cell migration assay) at a density of $1 \times 10^{5} /$ well, and $700 \mu 1$ RPMI-1640 medium containing 10\% FBS was added to the lower chamber to serve as a chemoattractant. After $72 \mathrm{~h}$ of incubation in a humidified cell culture incubator, the cells were fixed in cold $95 \%$ ethanol for $10 \mathrm{~min}$. The cells that remained on the upper side of the membranes were stained with $2 \mu \mathrm{g} / \mathrm{ml}$ DAPI (KPL, Inc., Gaithersburg, MD, USA) for $2 \mathrm{~min}$, room temperature and the invasive cells that had reached the lower side of the membranes were stained with $1 \mu \mathrm{g} / \mathrm{ml}$ propidium iodide (Sigma-Aldrich; Merck KGaA, Darmstadt, Germany) for 1 min. Cells in 12 different fields were counted under an inverted fluorescence microscope at x200 magnification connected to a digital camera with which images were captured. In order to eliminate the influence of non-specific factors, such as loading error, on the results of Transwell assay, the cell invasive capacity was defined as the ratio of invaded cell numbers to that of non-invaded cells, rather than counting only the numbers of invaded cells at bottom surface of the membrane. The experiments were repeated three times. The invasive capacity of a treated sample was normalized to that of the corresponding control. One-sample unpaired Student's t-test was used to test the differences of normalized invasive capacities of three independent experiments with the hypothetical value (set to 1 ).

Cytoskeleton Regulators $R^{2}$ Profiler PCR array. SW480-7 cells were plated in 6-well plates and transfected with miR-96-5p inhibitor or miRNA inhibitor negative control oligos $48 \mathrm{~h}$ prior to the PCR array. Total RNA was isolated using GeneJET RNA Purification kit (cat. no. K0731; Thermo Fisher Scientific, Inc.). The purity and concentration of total RNA were determined with a Nanodrop 1000 spectrophotometer (Thermo Fisher Scientific, Inc.), and RNA integrity was ascertained by agarose gel electrophoresis. 
Genomic DNA was removed by treatment with DNase I (cat.no. ED0521; Thermo Fisher Scientific), according to the manufacturer's protocol. RNA was reverse-transcribed to cDNA using RT $^{2}$ First Strand kit (cat. no. 330401; Qiagen), following the manufacturer's protocol. Subsequently, qPCR was performed using a 96-well Cytoskeleton Regulators $\mathrm{RT}^{2}$ Profiler PCR array (cat. no. PAHS-088ZA; Qiagen). The PCR cycling program was set as follows: Segment 1 , denaturing at $95^{\circ} \mathrm{C}$ for $10 \mathrm{~min}$; segment 2,40 amplification cycles of annealing at $95^{\circ} \mathrm{C}$ for $15 \mathrm{sec}$ and extension at $60^{\circ} \mathrm{C}$ for $1 \mathrm{~min}$. mRNA expression was normalized to the housekeeping gene GAPDH and the fold changes relative to the negative control were calculated. All data from the PCR array was analyzed by the Qiagen PCR Array Data Analysis Web Portal (www.SABiosciences.com/pcrarraydataanalysis.php.) using the $\Delta \Delta \mathrm{Cq}$ method (16).

Validation of the target genes. The six pairs of primers (Table III) were designed using the primer-BLAST interface of NCBI database (https://blast.ncbi.nlm.nih.gov/Blast.cgi, BLAST+2.8.1)and synthesizedby IntegratedDNATechnologies, Inc. (Skokie, IL, USA). Firstly, RNA isolation and DNase treatment were performed with the same protocols aforementioned. Then cDNA was synthesized with: $2 \mu 1$ DNA digested RNA $(500 \mu \mathrm{g} / \mu \mathrm{l})$ being mixed with $0.5 \mu \mathrm{l}$ oligo (dT) 18 primer $(0.5 \mu \mathrm{g} / \mu \mathrm{l})$ (cat. no. S0131; Thermo Fisher Scientific, Inc.) and $10 \mu 1$ diethyl pyrocarbonate treated water, then incubated at $65^{\circ} \mathrm{C}$ for $5 \mathrm{~min}$ and chilled on ice until reaching room temperature. A Master Mix was prepared, which contained $1 \mu 1$ ReverAid Reverse transcriptase (200 U/ $\mu$ l) (cat. no. EP0441; Thermo Fisher Scientific, Inc.) supplemented with $4 \mu 1$ $5 X$ Reaction buffer (Qiagen), $0.5 \mu 1$ Ribolock RNase inhibitor (40 U/ $\mu 1$; cat. no. EO0381; Thermo Fisher Scientific, Inc.) and $2 \mu 1$ dNTP (10 mM; cat. no. R0192; Thermo Fisher Scientific, Inc.). The synthesized cDNA was incubated at $-20^{\circ} \mathrm{C}$ until use. qPCR was performed with SYBR Select Master Mix (cat. no. 4472908; Thermo Fisher Scientific, Inc.). GAPDH was set as the reference gene according to the aforementioned protocol. Finally, the gene expression values of mRNAs were analyzed by normalizing with the internal control, GAPDH, and relative quantitation values were calculated (16).

Statistical analysis. Statistical analysis was performed using GraphPad InStat version 3.05 for Windows (GraphPad Software, Inc., San Diego, CA, USA), all data obtained in the RT-qPCR, viability, invasion, and migration were calculated by one sample t-test. Quantitative results were stated as the mean \pm standard deviation. A two-sided $\mathrm{P}<0.05$ was considered to indicate a statistically significant difference.

\section{Results}

Selection of aberrantly expressed miRNA in CRC tissues. A total of nine independent miRNA profiling studies in CRC (Table IV) were identified using the PubMed search. Intersection analysis with a 'Venn Diagram' demonstrated that four miRNAs were aberrantly expressed in three independent studies. One of the miRNAs identified was miR-96-5p, and studies with the remaining three miRNAs are currently underway.
Table III. Sequences of primers used in reverse transcription-quantitative polymerase chain reaction analysis.

\begin{tabular}{|c|c|}
\hline Gene & Primer \\
\hline \multirow[t]{2}{*}{ IQGAP2 } & Forward 5'-GCACACACTCACTCCTGTTG-3' \\
\hline & Reverse 5'-GTCAACTGCTCCTTCCCCAA-3' \\
\hline \multirow[t]{2}{*}{ CCNA1 } & Forward 5'-CGACTTTCGGACTACCAGGAA- \\
\hline & Reverse 5'-GGTCTTAAGGTCAAAGGACGA \\
\hline \multirow[t]{2}{*}{ PHLDB2 } & Foward 5'-CCAGGGAACGGGAAATGGAA-3 \\
\hline & Reverse 5'-GGTAGCGTGTCAAAGGACGA-3 \\
\hline \multirow[t]{2}{*}{ MYLK } & Forward 5'-GAGGACCCTGGGAAGATAA-3' \\
\hline & Reverse 5'-GAGCCAAGGCCCC AAGC-3' \\
\hline \multirow[t]{2}{*}{ BAIAP2 } & Forward 5'-GCCAGCGAG AGCCAGGGC-3' \\
\hline & Reverse 5'-GGAGCAGAAGGTGGAGCTG-3' \\
\hline \multirow[t]{2}{*}{ MACF1 } & Forward 5'-ACAGCCAGGG AGGAGGAC-3 \\
\hline & Reverse 5'-AGAAACAGA CTCCCAAAGA-3' \\
\hline \multirow[t]{2}{*}{ GAPDH } & Forward 5'-AATCCCATCACCATCTTCCA-3" \\
\hline & Reverse 5'-TGGACTCCACGACGTACTCA-3 \\
\hline
\end{tabular}

Expression of miR-96-5p in five CRC cell lines and tissue samples. RT-qPCR studies of miR-96-5p in five CRC cell lines demonstrated that its expression increased by 25.43 -fold in the HT29 cell line, 17.00-fold in the HCT116 cell line, 9.18-fold in the SW480 cell line, 7.86-fold in the SW620 cell line and 5.67-fold in the Caco2 cell line (Fig. 1A). A significant increase in the miR-96-5p expression in 26 primary CRC tissues, compared with apparently normal adjacent tissues, was also determined ( $3.32 \pm 3.35$ vs. $0.58 \pm 0.61 ; \mathrm{P}=0.01$; Fig. $1 \mathrm{~B})$

Effects of miR-96-5p inhibitor on the viability of three CRC cell lines. Following transfection optimization, only three out of the five CRC cell lines, HCT116, SW480 and SW620, were successfully transfected. HCT116 and SW620 were successfully transfected with Lipofectamine 2000 and SW480 with HiPerFect. HT29 and Caco2 could not be used for further experiments due to the transfecting reagents being toxic to these cell lines. The majority of HCT116, SW480 and SW620 cells died following transfection with Cell Death siRNA (data not shown). As miR-96-5p was aberrantly upregulated in CRC, CRC cells were transfected with the miR-96-5p inhibitor $6 \mathrm{~h}$ prior to the MTT assay, which was performed to detect cell viability (Fig. 2). The result indicated that the miR-96-5p inhibitor had no significant effects on the cell viability of the HCT116, SW480 and SW620 cell lines $(P>0.05)$.

In vitro selection of invasive CRC cells. A Matrigel invasion assay was conducted to determine the intrinsic invasive capabilities of the three CRC cell lines (Fig. 3). The result demonstrated that none of the three cell lines were suitable for the Matrigel invasion assay as there were there were no significant differences between upper and lower membrane. For HCT116 and SW620, almost no cells invaded through the Transwell inserts within $72 \mathrm{~h}$; however, for SW480, a limited number of cells invaded through the inserts (Fig. 3A). The 
Table IV. Summary of genome-wide microRNA profiling studies on CRC.

\begin{tabular}{|c|c|c|c|c|}
\hline Reference & Year & Technique & Stage of CRC & (Refs.) \\
\hline Brunet Vega et al & 2013 & Microarray analysis & Tx, N1-3 and M0 & $(22)$ \\
\hline Hamfjord et al & 2012 & Next generation sequencing & $\mathrm{T} 2-3, \mathrm{~N} 0-3$ and $\mathrm{Mx}$ & $(23)$ \\
\hline Callari et al & 2012 & Microarray analysis & $\mathrm{T} 2-4, \mathrm{Nx}$ and $\mathrm{Mx}$ & (24) \\
\hline Arndt et al & 2009 & Microarray analysis & T1-4, N0-3 and M0-1 & $(50)$ \\
\hline Motoyama et al & 2009 & Microarray analysis & T1-4, N0-1 and M0 & $(51)$ \\
\hline Sarver et al & 2009 & Microarray analysis & T3-4, N0-3 and M0-1 & $(52)$ \\
\hline Schepeler et al & 2008 & Microarray analysis & T3-4, N0 and M0 & $(53)$ \\
\hline Schetter et al & 2008 & Microarray analysis & T1-4, N0-3 and M0-1 & $(54)$ \\
\hline Bandres et al & 2006 & qPCR & T3-4, N0-3 and M0-1 & $(55)$ \\
\hline
\end{tabular}

CRC, colorectal cancer; T, tumor; N, node; M, metastasis. TNM staging recommended by AJCC (American Joint Committee on Cancer) (56).
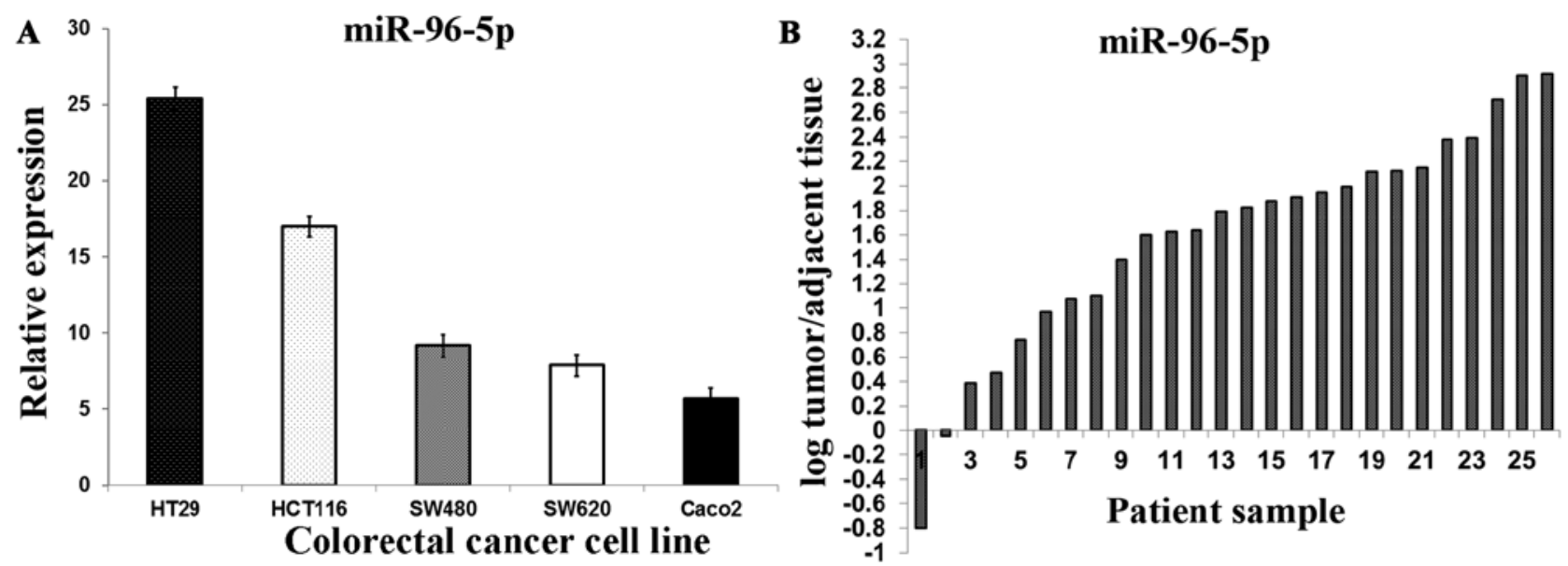

Figure 1. (A) The relative expression level of miR-96-5p in five CRC cell lines. Data represent the level of miRNA expression relative to that of reference gene, U6. (B) Quantitative analysis of miR-96-5p by reverse transcription-quantitative polymerase chain reaction in CRC tumor tissues and the corresponding normal adjacent tissues. The miRNA level was expressed as $\log ($ tumor/relative adjacent tissue). Each bar represents an individual patient. CRC, colorectal cancer; miR, microRNA.

Matrigel invasion assay system was used to select the invasive subpopulation from the original SW480 cell line. Original SW480 cells were subjected to serial passages through Matrigel-coated inserts and the invaded cells were transferred to a new insert (Fig. 3A). An invasive subpopulation called SW480-7 was derived in vitro by subjecting SW480 parental cells to seven sequential passages through the Matrigel-coated $8.0 \mu \mathrm{m}$ pore polycarbonate membrane (Fig. 3B). The average ratio of the invaded to non-invaded cell numbers was calculated from 12 fields for each membrane.

Expression of miR-96-5p in SW480-7 cells. To determine whether the expression of miR-96-5p was different in SW480-7 cells, compared with the parental SW480 cell line, qPCR was conducted (Fig. 3C). The results demonstrated no significant difference in the expression of miR-96-5p between SW480 and SW480-7 cells $(9.66 \pm 1$ h. 34 vs. $11.10 \pm 1.73 ; \mathrm{P}=0.3299)$. Statistical analysis was conducted with the unpaired Student's t-test.

Effects of the miR-96-5p inhibitor and mimic on the migration and invasion of SW480-7 cells. Cell migration assays were conducted following the transfection of SW480-7 cells with the miR-96-5p inhibitor or miR-inhibitor negative control for $48 \mathrm{~h}$. Significant inhibition of migration of SW480-7 cells was determined in miR-96-5p inhibitor-transfected cells, as expected $(\mathrm{P}=0.0329$, Fig. $4 \mathrm{~A})$; however, Matrigel cell invasion assays demonstrated that miR-96-5p inhibition had no effect on cell invasion ( $\mathrm{P}>0.05$, Fig. 4B). In parallel, miR-96-5p mimic or miR-mimic negative control was also transfected into SW480-7 cells for $48 \mathrm{~h}$ followed by Transwell migration and Matrigel invasion assays. Transfection with the miR-96-5p mimic in SW480-7 cells significantly promoted the cell migration $(\mathrm{P}=0.03)$ and invasion $(\mathrm{P}=0.0369)$ (Fig. 4C and $\mathrm{D})$.

Cytoskeleton Regulator $R T^{2}$ Profiler PCR array. miR-96-5pinhibitor-transfected SW480-7 cells induced a higher expression of numerous genes, which are known to be associated with the regulation of cytoskeleton dynamics, compared with the SW480-7 cells transfected with miRNA inhibitor control. The expression of six genes, including myosin light chain kinase 2 (MYLK2), pleckstrin homology like domain family B member 2 (PHLDB2), cyclin A1 
A

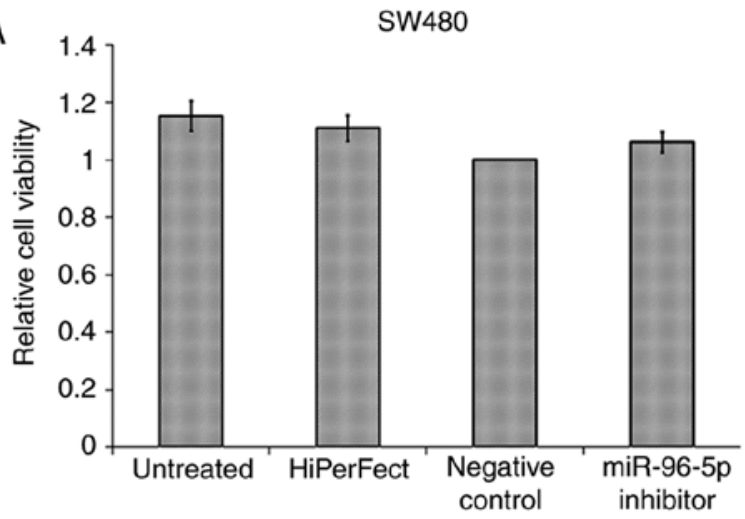

B

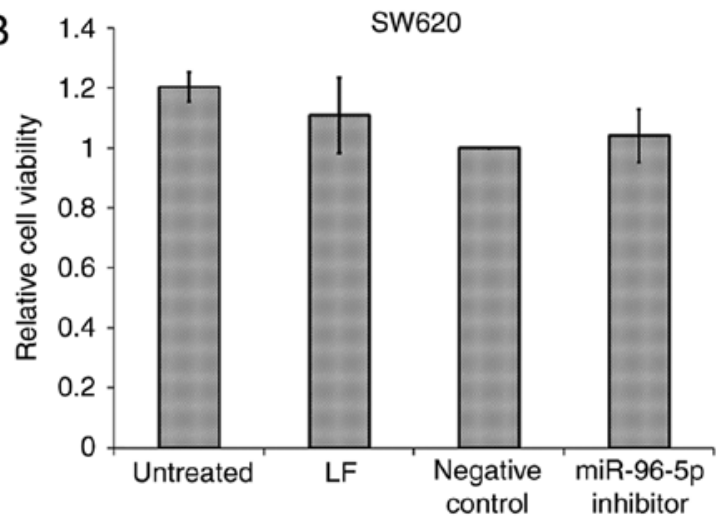

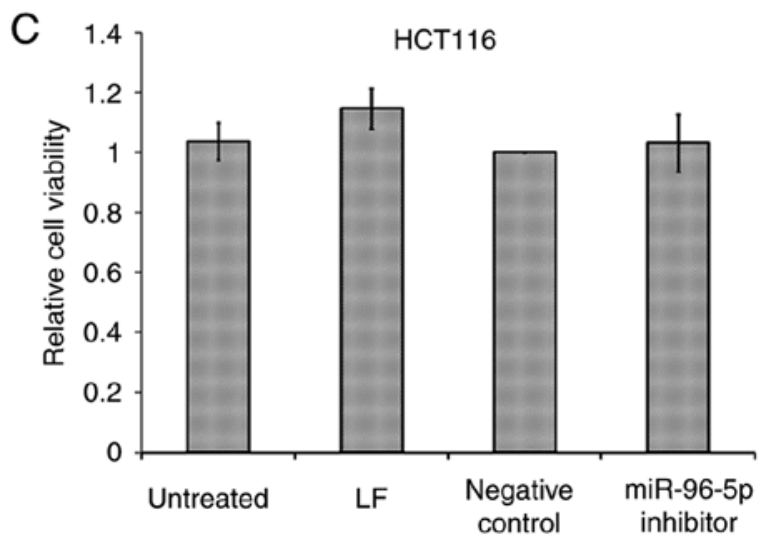

Figure 2. Effects of miRNA-96-5p inhibitor on cell viability of (A) SW480, (B) SW620 and (C) HCT116. The values of cell viability were normalized with that of the corresponding negative control group. Untreated, only medium treated cells; LF, only Lipofectamine 2000 with medium treated cells; HiPerFect, only HiPerFect with medium treated cells; negative control, transfection with miR inhibitor control and cultured with medium; miR-96-5p, transfection with miR-96 inhibitor and cultured with medium. Data represent the mean \pm SD of three independent experiments, each performed in triplicate.

(CCNA1), IQ motif containing GTPase activating protein 2 (IQGAP2), Brain-specific angiogenesisinhibitor 1-associated protein 2 (BAIAP2) and microtubule-actin crosslinking factor 1 (MACF1), was increased by $>2.5$ fold (Table ) in inhibitor transfected cells compared with inhibitor control transfected cells.

Validation of PCR array data at a mRNA level through $R T-q P C R$. The validation results of $\mathrm{RT}^{2}$ Profiler PCR array are summarized in Fig. 5. The corresponding expression levels of control groups were used as calibrators, which were set as one, and relative mRNA expression of each gene was compared with the control group. As a result, mRNA expression levels of MYLK2, PHLDB2, CCNA1, IQGAP2, BAIAP2 and MACF1 in SW480-7 cells transfected with the miR-96-5p inhibitor were increased significantly, whilst the expression of IQGAP had the largest fold change. For MYLK2, PHLDB2, CCNA1, BAIAP2 and MACF1, the increase in mRNA expression in miR-96-5p inhibitor-transfected cells was 5.6-, 3.2- 5.4-, 4.8- and 6.7-fold, respectively (Fig. 5A). Furthermore, miR-96-5p mimic-transfection reversed the effect of the miR-96-5p inhibitor, whereby the expression of all these six mRNA was decreased (Fig. 5B).

\section{Discussion}

Increasing evidence has established that miRNA dysregulation is involved in multiple cellular characteristics of CRC
Table V. Differentially expressed genes mediated by miRNA-96-5p inhibitor.

\begin{tabular}{lc}
\hline Gene & Fold regulation \\
\hline MYLK2 & 4.8906 \\
PHLDB2 & 3.2944 \\
CCNA1 & 5.8679 \\
IQGAP2 & 8.7321 \\
BAIAP2 & 4.7132 \\
MACF1 & 6.5491 \\
\hline
\end{tabular}

MYLK2, myosin light chain kinase 2; PHLDB2, pleckstrin homology-like domain, family B, member 2; CCNA1, cyclin A1; IQGAP2, IQ motif containing GTPase activating protein 2; BAIAP2, brain-specific angiogenesisinhibitor 1-associated protein 2; MACF1, microtubule-actin crosslinking factor 1 .

including proliferation, apoptosis, cell cycle, migration and invasion (17-20). miR-96-5p is a member of the miR-183 family consisting of three members, including miR-96, miR-182 and miR-183 (21). A number of published miRNA profiling studies indicated that miR-96-5p is upregulated in CRC tissues, compared with apparently normal adjacent tissues (22-24). To further investigate the biological function of miR-96-5p in CRC, the miR-96-5p inhibitor was 
A

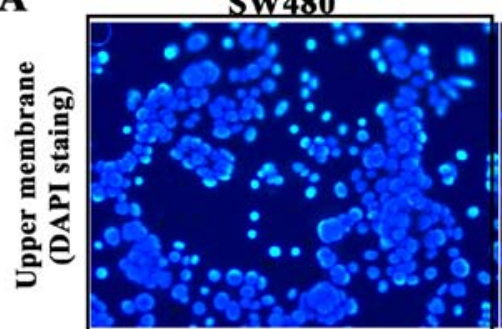

HCT116

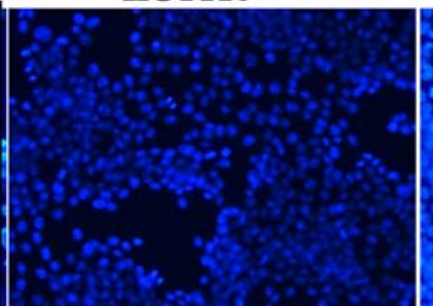

SW620

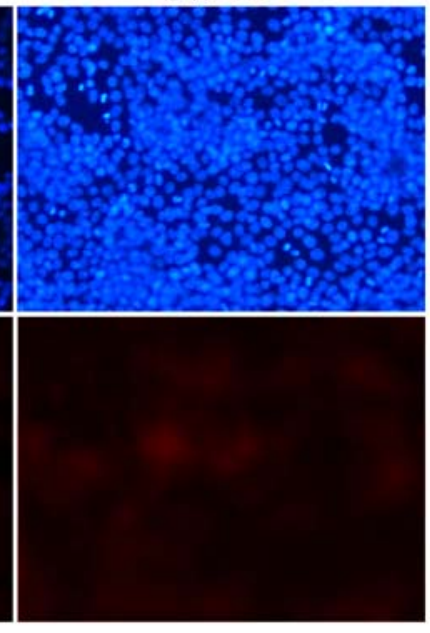

$\mathbf{C}_{14}$

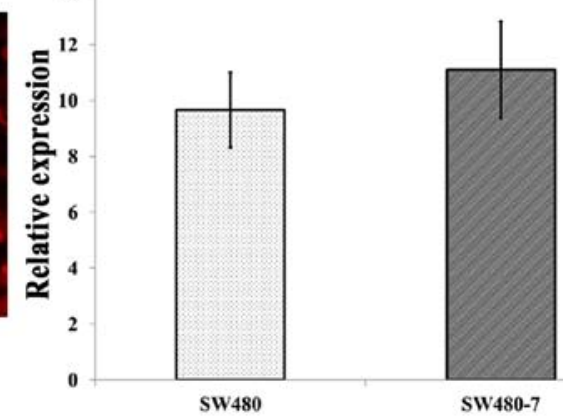

Figure 3. The invasive capabilities of the three colorectal cancer cell lines and in vitro selection of invasive subpopulation from SW480 cells by a Matrigel assay. The two images in each row are the photos of upper (blue) and lower (red) membrane surfaces captured from the same field which was observed with Olympus BX51 fluorescence microscope (Olympus Corp.) in a zig-zag pattern under x200 magnification. (A) The invasive capabilities of HCT116, SW480 and SW620. (B) An invasive subpopulation, SW480-7, was selected from SW480 cells. (C) The expression of miR-96-5p in SW480 and SW480-7 cells. Data represent the level of miRNA expression relative to that of reference gene, U6. The means \pm standard deviations were calculated from the data of three independent experiments. PI, propidium iodide; miRNA, microRNA.
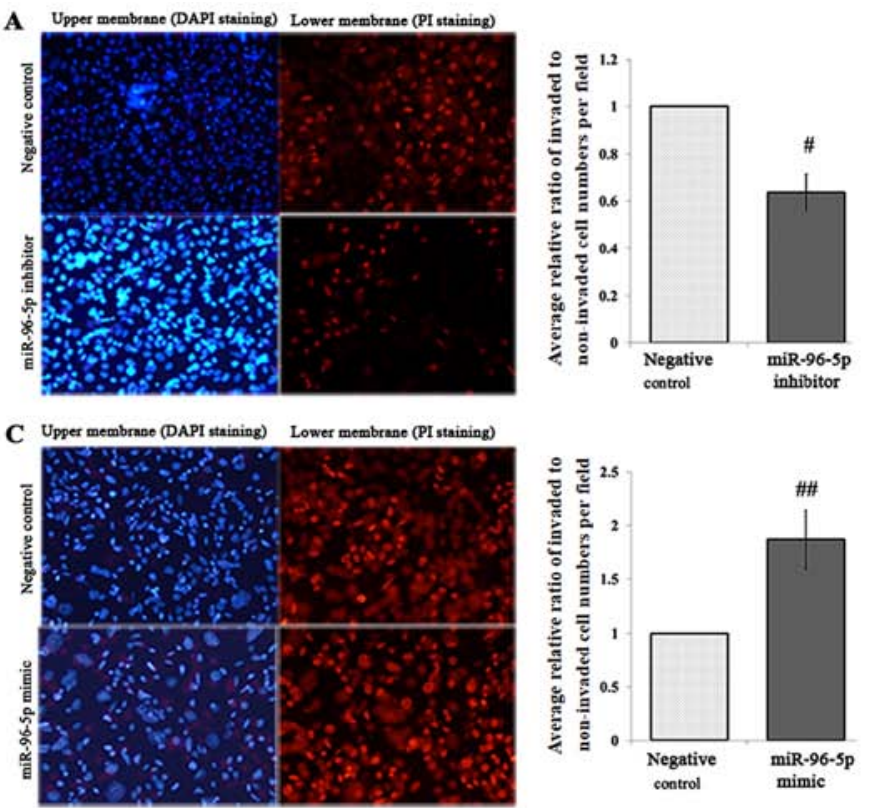
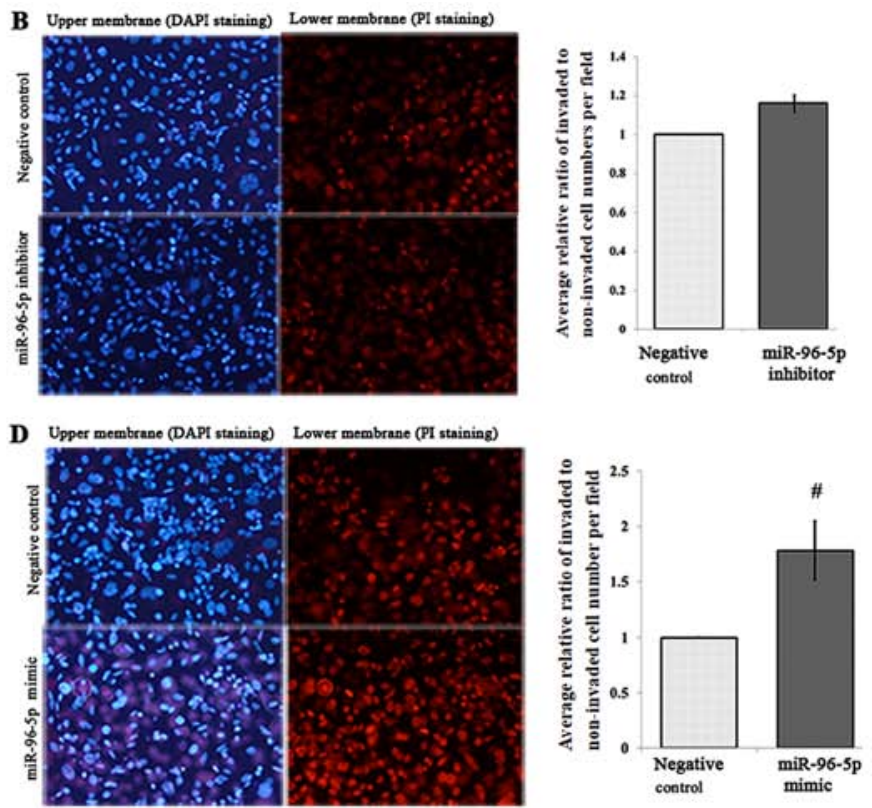

Figure 4. Transwell assay of SW480-7 colorectal cancer cells transfected with miR negative control, miR-96-5p mimic and inhibitor. The blue cells in upper membrane were stained by DAPI, and cells in the lower membrane were stained by PI. The cells were counted under a light microscope (x200 magnification) in five randomly selected fields. Bars represent the number of invaded cells. (A) The effect of miR-96-5p inhibitor on cell migration. (B) The effect of miR-96-5p inhibitor on cell invasion. (C) The effect of miR-96-5p mimic on cell migration. (D) The effect of miR-96-5p mimic on cell invasion. ${ }^{\#} \mathrm{P}<0.01$, ${ }^{\mathrm{P}}<0.05$ vs. negative control. PI, propidium iodide; miR, microRNA. 

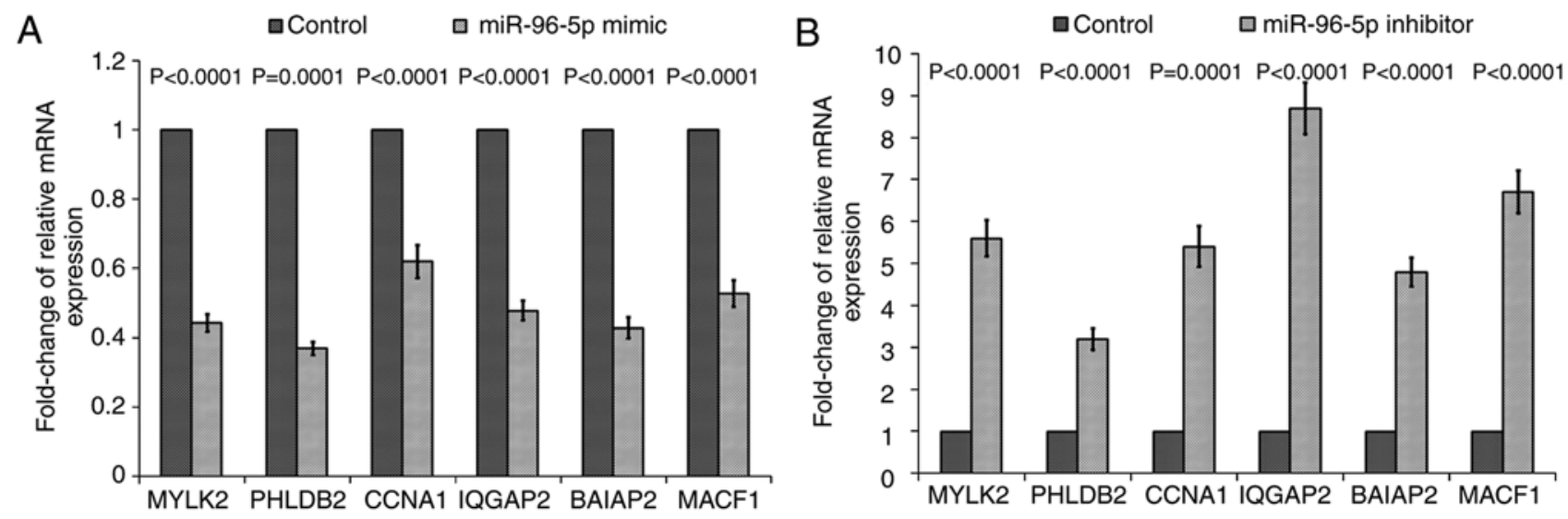

Figure 5. The mRNA expression of selected mRNAs (MYLK2, PHLDB2, CCNA1, IQGAP2, BAIAP2 and MACF1) in miR-96-5p inhibitor/mimic transfected SW480-7 cells by reverse transcription-polymerase chain reaction. The relative mRNA expression in SW480-7 cells transfected with (A) miR-96-5p inhibitor and (B) miR-96-5p mimic. The ratio of mRNA expression in the inhibitor/mimic-transfected groups relative to the corresponding negative control was calculated. Data are presented as the mean \pm standard deviation from three independent experiments. Statistical analysis was conducted using one-sample Student's t-test. P-values are as shown in the bar chart. MYLK2, myosin light chain kinase 2; PHLDB2, pleckstrin homology like domain family B member 2; CCNA1, cyclin A1; IQGAP2, IQ motif containing GTPase activating protein 2; BAIAP2, Brain-specific angiogenesis inhibitor 1-associated protein 2; MACF1, microtubule-actin crosslinking factor 1; miR, microRNA.

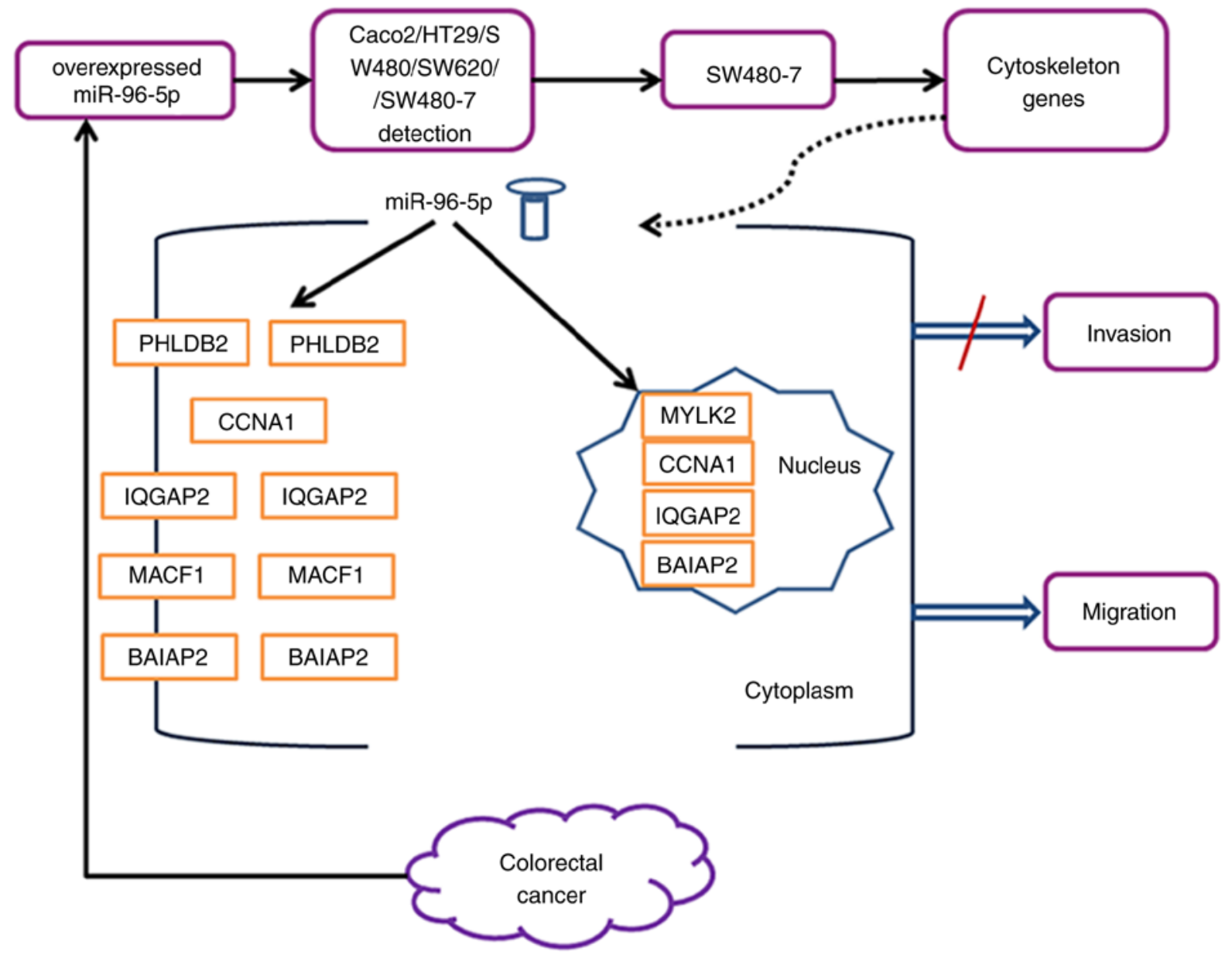

Figure 6. Hypothetical model showing downregulation of the cytoskeleton genes and promotion of migration by miR $965 \mathrm{p}$ in CRC.

introduced into SW480-7 cells by transient transfection. Due to miR-96-5p inhibitor exerting its function through inhibiting the endogenous miR-96-5p, the expression level of miR-96-5p in the five CRC cell lines, including HCT116, HT29, Caco2,
SW480 and SW620, was detected prior to transfection. To the best of our knowledge, the present study indicated for the first time that miR-96-5p was detectable in all five of these CRC cell lines. 
The development of metastasis is a major cause of mortality in patients with $\mathrm{CRC}$, and migration and invasion are two cellular characteristics associated with metastasis in vitro. In the present study, the Transwell assay system was used to evaluate the effect of miR-96-5p on the cell invasion and migration of CRC cells in vitro. The Transwell migration and Matrigel invasion assays have been frequently used to determine the cell motility of cancer cells in vitro. The original technique for assessing the migratory capacity of polymorphonuclear leucocytes was introduced by Boyden in 1962 (25). Currently, the modified migration assay is performed with commercially available plastic inserts compatible with multi-well plates. The bottom of the plastic insert contains a microporous membrane allowing migratory cells to migrate to the other side of the membrane. Due to Transwell Permeable Supports typifying the most commonly used plastic inserts, this plastic insert-based migration assay type is frequently termed a Transwell migration assay. To determine cell invasion, a gel, which is referred to as Matrigel, containing similar components with a basement membrane, is formed on the microporous membrane (26). The only difference between the migration and invasion assays is the presence of Matrigel, which is intended to mimic the barrier that cancer cells encounter in the process of invasion.

In migration and invasion assays, the cell numbers used in the control group and treatment groups are identical at the beginning of the experiment. If miR-96-5p regulates the cell growth of CRC cells, the cell numbers in the control group and treatment groups will be significantly different and the invasion data between treatment groups will be not statistically different. An MTT assay was performed to assess the influence of miR-96-5p on the cell viability of the HCT116, SW480 and SW620 cell lines, which indicated that miR-96-5p had no effect on the viability of the three cell lines.

Invasion and migration assays were conducted using Transwell inserts as described previously (27) with a number of modifications. The original SW480 cell line has been used for invasion assays in previous studies $(28,29)$ to assess the invasiveness of SW480 cells by counting the cell number of invasive cells at the bottom of the insert. Previously, an improved method was used to quantify the invasiveness of cancer cells by calculating the ratio of invasive cells to non-invasive cells (30). As depicted in Fig. 3A, only a limited number of cells invaded through the Matrigel-coated Transwell inserts. Due to miR-96-5p overexpression in CRC, miR-96-5p inhibition was expected to suppress the cell invasion of SW480 cells; therefore, more invasive $\mathrm{CRC}$ cell lines are required to evaluate the effect of the miR-96-5p inhibitor on cell invasion. A common method to gain an invasive subpopulation from an established cancer cell line is to isolate invasive cells with Transwell inserts in vitro $(31,32)$. An invasive subpopulation, SW480-7, was derived in vitro by subjecting SW480 parental cells to 7 sequential passages through Matrigel-coated Transwell inserts (Fig. 3B).

miR-96-5p inhibitor targeting endogenous miR-96-5p was utilized to perform a loss-of-function study. RT-qPCR results demonstrated that the level of miR-96-5p in SW480-7 cells was not altered, compared with the original SW480 cell line (Fig. 4). In accordance with the previous study, miRNA-96-5p acted as an oncogene in CRC cells in vitro (33). The results of the Transwell migration assay demonstrated that the miR-96-5p inhibitor suppressed cell migration in SW480-7 cells; however, in the invasion assay, the miR-96-5p inhibitor did not block SW480-7 cell invasion through the Matrigel-coated Transwell inserts. This may be due to a number of components of Matrigel, which may have counteracted the ability of the miR-96-5p inhibitor to block cell invasion.

In order to further investigate the molecular changes in miR-96-5p inhibitor-transfected SW480-7 cells, comparative gene expression analysis was performed using the Cytoskeleton Regulator $\mathrm{RT}^{2}$ Profiler PCR array. A number of genes were upregulated in SW480-7 cells transfected with the miR-96-5p inhibitor. For example, a 5.6 fold increase in the expression of MYLK2 was observed following miR-96-5p inhibitor transfection. Stress fibers, which are made up of prominent bundles of actin filaments and myosin II filaments, serve an essential role in cell migration. The myosin regulatory light chain (MLC), a component of myosin II, is the target component regulated by MYLK and myosin light chain phosphatase. Only the active monomer of myosin II with phosphorylated MLC are able to associate with other myosin II molecules assembling into myosin II filaments (34). In the present study, cell migration was suppressed by miR-96-5p inhibition, and MYLK2 was expected to be downregulated; however, MYLK2 was upregulated in miR-96-5p inhibitor-treated SW480 cells, indicating that the Cytoskeleton Regulatory pathway serves a role in miR-96-5p inhibitor-induced suppression of cell migration as negative regulators. Besides PHLDB2, the genes MYLK2 and IQGAP2 have also been reported as negative regulators of cell migration and/or invasion. Knockdown of MYLK by siRNAs in breast epithelial cells has been demonstrated to result in increased cell migration and invasion, disruption of cell-cell adhesions and enhanced formation of focal adhesions at the leading edge of migratory cells (35). Cell migration/invasion was also increased following IQGAP2 knockdown and impaired following overexpression of IQGAP2 in CRC and prostate cancer cells $(36,37)$. Although the CCNA1 gene has not been reported as a negative regulator of cell migration, its family member CCNA2 gene has been indicated to negatively control cell motility by promoting Ras homology family member A activation (38). To the best of our knowledge, BAIAP2 and MACF1 genes are required for the migration function (39); however, their negative role in migration in different cell types may be possible, similar to other cytoskeletal regulatory genes, including MYLK2, IQGAP2 and CCNA1. Thus, the increased expression of these cytoskeleton regulator genes, which are negative regulators of cell migration and/or invasion, is consistent with our data on the inhibition of migration by the miR-96-5p inhibitor. Fig. 6 summarizes the findings of the present study.

It is possible that target prediction will demonstrate that miR-96-5p can interact with other genes besides MYLK2, PHLDB2, CCNA1, IQGAP2, BAIAP2 and MACF1, which were used in the 96-well Cytoskeleton Regulators $\mathrm{RT}^{2}$ Profiler PCR array. Other miRNAs that can interact with MYLK2, PHLDB2, CCNA1, IQGAP2, BAIAP2 and MACF1 can also be determined by target prediction. The identity of these other genes and miRNAs are worthy of further investigation in the future.

Another limitation of the present study was the inability to associate the expression of these mRNAs with protein 
expression. Future studies to verify this using western blotting, or cytochemical or immunofluorescence staining are required. Due to only the SW480-7 cell line being used, similar studies are required using other cell lines.

The extracellular matrix (ECM) is a major component of tumor microenvironment (40). Matrigel is used as a substitute ECM in invasion assays, and was only considered as a barrier against cancer cell invasion; however, increasing numbers of studies have demonstrated that cancer cells are not only affected by the architecture of Matrigel mechanically, but also influenced by certain components biochemically (38). The Matrigel comprises of laminin, collagen IV, entactin/nidogen, heparan sulfate proteoglycans and a number of growth factors $(41,42)$. Previous studies have demonstrated that Matrigel promotes cell invasion and gene expression changes by activating integrins and other transmembrane receptors (43). The RMCCA1 cells, a cholangiocarcinoma cell line, cultured with a coating of Matrigel are more invasive than cells maintained in Matrigel-free plates. The protein expression profile indicated that the expression of the actin-binding protein L-plastin is upregulated by Matrigel, and the subsequent loss-of-function study, using siRNA, demonstrated that the knockdown of L-plastin reduces cell invasion induced by Matrigel (44). Vimentin, an intermediate filament protein type, is associated with a high degree of invasiveness $(45,46)$. It is considered that Matrigel can promote cell invasion of head and neck squamous cell carcinoma cells through increasing vimentin expression in vitro (47).

Furthermore, more recent observations have indicated that Matrigel has an influence on cell invasion by altering the expression of miRNAs in cancer cells. miRNA profiling of two CRC cell lines, SW480 and SW620, was performed via a microarray assay to investigate the effect of Matrigel on miRNA expression (46). When comparing the miRNA expression signatures between the cells cultured on plastic and Matrigel, numerous differentially expressed miRNAs were identified. Furthermore, a number of miRNAs with altered expression were observed in SW480 and SW620 cells, indicating that Matrigel may induce a particular miRNA panel across various cancer cell lines. To test this hypothesis, four notably affected miRNAs in both cell lines, including miR-32, miR-29b, miR-1290 and miR-210, were detected in five epithelial cancer cell lines, including SW480, SW620, A549, HT29 and MDA-MB-231. Three out of the four miRNAs detected, miRNA-32, miRNA-29b and miRNA-1290, exhibited consistent alterations across all five of the cancer cell lines. Functional studies indicated that Matrigel-mediated miRNA-210 overexpression may promote the invasion of SW480 cells by decreasing the expression of vacuole membrane protein 1 (48). All of the studies aforementioned provide evidence to demonstrate that Matrigel can stimulate cell invasion by altering the expression of relevant genes.

In the present study, the invasiveness of SW480-7 cells subjected to a Matrigel invasion assay was affected by two factors: miR-96-5p inhibitor and Matrigel, whilst the migratory capacity assessed via a Transwell migration assay was influenced by the miR-96-5p inhibitor only. The present study indicated that the miR-96-5p inhibitor suppressed the cell migration of SW480-7 cells, but had no influence on the cell invasion. The difference in results may be attributable to the usage of Matrigel in invasion assay, due to it being the only difference between the invasion and migration assays. The most possible explanation is that the pathways implicated in the cell invasion of SW480-7 cells are regulated by biochemical components of Matrigel and miR-96-5p. It is possible that the effect of the miR-96-5p inhibitor blockade on cell invasion was opposed by the stimulation of cell invasion by the effects of Matrigel, as aforementioned. As a result, miR-96-5p inhibition had no effect on cell invasion. The effects of Matrigel on miR-96-5p-transfected cells require further investigation. The mechanisms underlying the promotion of cell migration and invasion by the miR-96-5p mimic in SW480-7 cells also require further investigation. Due to the SW480-7 cell line being used, the present study requires investigation with other cell lines in the future.

As summarized in Table $\mathrm{V}$, numerous studies have demonstrated that miR-96-5p is overexpressed in cancer tissues, compared with matched normal adjacent tissues, indicating an oncogenic role for miR-96-5p. This is consistent with our in vitro observations, whereby increased cell migration and invasion was determined in miR-96-5p mimic-transfected SW480-7 cells and the miR-96-5p inhibitor blocked cell migration; however, Ress et al (49) demonstrated that there was a decrease in growth of HCT116 cells, thus supporting the role of miR-96-5p as a tumor suppressor. This may be due to the fact that miRNAs can act as oncogenes or tumor suppressors depending on the cellular context, as indicated by Arndt et al (50), whereby miR-145 acted as an oncogene in HCT8 and SW620 cells, but indicated a tumor suppressive role in SW480 cells (50).

To conclude, it was observed that migration of SW480-7 cells was blocked by the miR-96-5p inhibitor; however, invasion was not blocked, indicating that Matrigel not only functions as a molecular scaffold but can also influence cancer cell invasion by involving other biochemical components, such as integrins and other transmembrane receptors, and activating signaling pathways. The blockade of cell invasion by miR-96-5p inhibitor may be counteracted by the stimulatory effects of Matrigel on cell invasion; thus, the underlying mechanisms involving Matrigel components in miR-96-5p inhibitor-transfected SW480-7 is worthy of further investigations in the future.

\section{Acknowledgements}

The authors would like to express their appreciation to Mr. Samuel Leon Juan Khoo for helpful discussion on experimental techniques.

\section{Funding}

Funding support was received from Hebei Provincial of Human Resources and Social Security (CY201701), Chengde Medical Key Project (201813) the University Putra Malaysia (grant no. GP-IPS/2014/943395) and the Malaysian Ministry of Science, Technology and Innovation (grant no. 02-01-04-SF1312).

\section{Availability of data and materials}

The datasets used and/or analyzed during the current study are available from the corresponding author on reasonable request. 


\section{Authors' contributions}

PYH, WKY, and HFS designed the study. PYH performed the experiments. MFJ, NM, and NMD contributed to the data analysis. PYH wrote the manuscript. All authors read and approved the final manuscript.

\section{Ethics approval and consent to participate}

Ethics approval was obtained from the National Medical Ethics Board (approval no. NMRR-12-435-11565), and study participants provided written informed consent.

\section{Patient consent for publication}

Not applicable.

\section{Competing interests}

The authors declare that they have no competing interests.

\section{References}

1. Arnold M, Sierra MS, Laversanne M, Soerjomataram I, Jemal A and Bray F: Global patterns and trends in colorectal cancer incidence and mortality. Gut 66: 683-691, 2017.

2. Brody H: Colorectal cancer. Nature 521: S1, 2015.

3. Bockhorn J, Yee K, Chang YF, Prat A, Huo D, Nwachukwu C, Dalton R, Huang S, Swanson KE, Perou CM, et al: MicroRNA-30c targets cytoskeleton genes involved in breast cancer cell invasion. Breast Cancer Res Treat 137: 373-382, 2013.

4. Valeri N, Braconi C, Gasparini P, Murgia C, Lampis A, Paulus-Hock V, Hart JR, Ueno L, Grivennikov SI, Lovat F, et al MicroRNA-135b promotes cancer progression by acting as a downstream effector of oncogenic pathways in colon cancer. Cancer Cell 25: 469-483, 2014

5. Friedman RC, Farh KK, Burge CB and Bartel DP: Most mammalian mRNAs are conserved targets of microRNAs. Genome Res 19: 92-105, 2009.

6. Xiao R, Li C and Chai B: miRNA-144 suppresses proliferation and migration of colorectal cancer cells through GSPT1. Biomed Pharmacother 74: 138-144, 2015.

7. Ye J, Wu X, Wu D, Wu P, Ni C, Zhang Z, Chen Z, Qiu F, Xu J and Huang J: miRNA-27b targets vascular endothelial growth factor $\mathrm{C}$ to inhibit tumor progression and angiogenesis in colorectal cancer. PLoS One 8: e60687, 2013

8. Mo JS, Alam KJ, Kang IH, Park WC, Seo GS, Choi SC, Kim HS, Moon HB, Yun KJ and Chae SC: MicroRNA 196B regulates FAS-mediated apoptosis in colorectal cancer cells. Oncotarget 6: 2843-2855, 2015.

9. Sun P, Sun D, Wang X, Liu T, Ma Z and Duan L: miR-206 is an independent prognostic factor and inhibits tumor invasion and migration in colorectal cancer. Cancer Biomark 15: 391-396, 2015.

10. Cristóbal I, Madoz-Gúrpide J, Manso R, Rojo $F$ and García-Foncillas J: miR-29c downregulation contributes to metastatic progression in colorectal cancer. Ann Oncol 26 2199-2200, 2015.

11. Li C, Du X, Tai S, Zhong X, Wang Z, Hu Z, Zhang L, Kang P, Ji D, Jiang X, et al: GPC1 regulated by miR-96-5p, rather than miR-182-5p, in inhibition of pancreatic carcinoma cell proliferation. Int J Mol Sci 15: 6314-6327, 2014.

12. Larne O, Martens-Uzunova E, Hagman Z, Edsjö A, Lippolis G, den Berg MS, Bjartell A, Jenster $\mathrm{G}$ and Ceder Y: miQ-a novel microRNA based diagnostic and prognostic tool for prostate cancer. Int J Cancer 132: 2867-2875, 2013.

13. Assal RA, EI Tayebi HM, Hosny KA, Esmat G and Abdelaziz AI: A pleiotropic effect of the single clustered hepatic metastamiRs miR-96-5p and miR-182-5p on insulin-like growth factor II, insulin-like growth factor-1 receptor and insulin-like growth factor-binding protein-3 in hepatocellular carcinoma. Mol Med Rep 12: 645-650, 2015
14. Oliveros JC (2015). Venny. An interactive tool for comparing lists with Venn's diagrams. http://bioinfogp.cnb.csic.es/tools/venny/ index.html. Accessed June 12, 2013.

15. Cikos S, Bukovská A and Koppel J: Relative quantification of mRNA: Comparison of methods currently used for real-time PCR data analysis. BMC Mol Biol 8: 113, 2007.

16. Livak KJ and Schmittgen TD: Analysis of relative gene expression data using real-time quantitative PCR and the 2(-Delta Delta C(T)) method. Methods 25: 402-408, 2001.

17. Qiu Z, Guo W, Wang Q, Chen Z, Huang S, Zhao F, Yao M, Zhao Y and He X: MicroRNA-124 reduces the pentose phosphate pathway and proliferation by targeting PRPS1 and RPIA mRNAs in human colorectal cancer cells. Gastroenterology 149: 1587-1598.e11, 2015

18. Fujiya M, Konishi H, Mohamed Kamel MK, Ueno N, Inaba Y, Moriichi K, Tanabe $\mathrm{H}$, Ikuta $\mathrm{K}$, Ohtake $\mathrm{T}$ and Kohgo Y: microRNA-18a induces apoptosis in colon cancer cells via the autophagolysosomal degradation of oncogenic heterogeneous nuclear ribonucleoprotein A1. Oncogene 33: 4847-4856, 2014.

19. Christensen LL, Tobiasen H, Holm A, Schepeler T, Ostenfeld MS, Thorsen K, Rasmussen MH, Birkenkamp-Demtroeder K, Sieber OM, Gibbs P, et al: miRNA-362-3p induces cell cycle arrest through targeting of E2F1, USF2 and PTPN1 and is associated with recurrence of colorectal cancer. Int J Cancer 133: 67-78, 2013.

20. Guo H, Chen Y, Hu X, Qian G, Ge S and Zhang J: The regulation of Toll-like receptor 2 by miR-143 suppresses the invasion and migration of a subset of human colorectal carcinoma cells. Mol Cancer 12: 77, 2013.

21. Pierce ML, Weston MD, Fritzsch B, Gabel HW, Ruvkun G and Soukup GA: MicroRNA-183 family conservation and ciliated neurosensory organ expression. Evol Dev 10: 106-113, 2008.

22. Brunet Vega A, Pericay C, Moya I, Ferrer A, Dotor E, Pisa A, Casalots A, Serra-Aracil X, Oliva JC, Ruiz A and Saigí E: microRNA expression profile in stage III colorectal cancer: Circulating miR-18a and miR-29a as promising biomarkers. Oncol Rep 30: 320-326, 2013.

23. Hamfjord J, Stangeland AM, Hughes T, Skrede ML, Tveit KM, Ikdahl T and Kure EH: Differential expression of miRNAs in colorectal cancer: Comparison of paired tumor tissue and adjacent normal mucosa using high-throughput sequencing. PLoS One 7: e34150, 2012.

24. Callari M, Dugo M, Musella V, Marchesi E, Chiorino G, Grand MM, Pierotti MA, Daidone MG, Canevari S and De Cecco L: Comparison of microarray platforms for measuring differential microRNA expression in paired normal/cancer colon tissues. PLoS One 7: e45105, 2012.

25. Boyden S: The chemotactic effect of mixtures of antibody and antigen on polymorphonuclear leucocytes. J Exp Med 115: 453-466, 1962.

26. Marshall J: Transwell(®) invasion assays. Methods Mol Biol 769, 97-110, 2011.

27. Borley AC, Hiscox S, Gee J, Smith C, Shaw V, Barrett-Lee P and Nicholson RI: Anti-oestrogens but not oestrogen deprivation promote cellular invasion in intercellular adhesion-deficient breast cancer cells. Breast Cancer Res 10: R103, 2008.

28. Rogers MA, Kalter V, Marcias G, Zapatka M, Barbus S and Lichter P: CITED4 gene silencing in colorectal cancer cells modulates adherens/tight junction gene expression and reduces cell proliferation. J Cancer Res Clin Oncol 142: 225-237, 2016.

29. Zhong G, Li H, Shan T and Zhang N: CSN5 silencing inhibits invasion and arrests cell cycle progression in human colorectal cancer SW480 and LS174T cells in vitro. Int J Clin Exp Pathol 8: 2809-2815, 2015

30. Yip WK, Cheenpracha S, Chang LC, Ho CC and Seow HF: Anti-proliferative and anti-invasive properties of a purified fraction from Streptomyces sp. H7372. Int J Oncol 37: 1229-1241, 2010.

31. Chu YW, Yang PC, Yang SC, Shyu YC, Hendrix MJ, Wu R and Wu CW: Selection of invasive and metastatic subpopulations from a human lung adenocarcinoma cell line. Am J Respir Cell Mol Biol 17: 353-360, 1997.

32. Smith JJ, Deane NG, Wu F, Merchant NB, Zhang B, Jiang A, Lu P, Johnson JC, Schmidt C, Bailey CE, et al: Experimentally derived metastasis gene expression profile predicts recurrence and death in patients with colon cancer. Gastroenterology 138: 958-968, 2010. 
33. Gao $\mathrm{F}$ and Wang W: MicroRNA-96 promotes the proliferation of colorectal cancer cells and targets tumor protein p53 inducible nuclear protein 1, forkhead box protein O1 (FOXO1) and FOXO3a. Mol Med Rep 11: 1200-1206, 2015

34. Vicente-Manzanares M, Ma X, Adelstein RS and Horwitz AR Non-muscle myosin II takes centre stage in cell adhesion and migration. Nat Rev Mol Cell Biol 10: 778-790, 2009.

35. Kim DY and Helfman DM: Loss of MLCK leads to disruption of cell-cell adhesion and invasive behavior of breast epithelial cells via increased expression of EGFR and ERK/JNK signaling. Oncogene 35: 4495-4508, 2016.

36. Gröschl BM, BettstetterT, WidmannF, Hofstädter W and Dietmaier W: IQGAP2 is downregulated in colorectal cancer (CRC) and involved in cellular migration. Cancer Res 74 (Suppl 19): 5004, 2014.

37. Xie Y, Yan J, Cutz JC, Rybak AP, He L, Wei F, Kapoor A, Schmidt VA, Tao L and Tang D: IQGAP2, A candidate tumour suppressor of prostate tumorigenesis. Biochim Biophys Acta 1822: 875-884, 2012.

38. Arsic N, Bendris N, Peter M, Begon-Pescia C, Rebouissou C, Gadéa G, Bouquier N, Bibeau F, Lemmers B and Blanchard JM: A novel function for Cyclin A2: Control of cell invasion via RhoA signaling. J Cell Biol 196: 147-162, 2012.

39. Nakamura N, Oshiro N, Fukata Y, Amano M, Fukata M, Kuroda S, Matsuura Y, Leung T, Lim L and Kaibuchi K: Phosphorylation of ERM proteins at filopodia induced by $\mathrm{Cdc} 42$. Genes Cells 5: 571-581, 2000.

40. Lu P, Weaver VM and Werb Z: The extracellular matrix: A dynamic niche in cancer progression. J Cell Biol 196: 395-406, 2012.

41. Kleinman HK, McGarvey ML, Liotta LA, Robey PG, Tryggvason K, Martin GR: Isolation and characterization of type IV procollagen, laminin, and heparan sulfate proteoglycan from the EHS sarcoma. Biochemistry 21: 6188-6193, 1982.

42. Vukicevic S, Kleinman HK, Luyten FP, Roberts AB, Roche NS and Reddi AH: Identification of multiple active growth factors in basement membrane Matrigel suggests caution in interpretation of cellular activity related to extracellular matrix components. Exp Cell Res 202: 1-8, 1992.

43. Hood JD and Cheresh DA: Role of integrins in cell invasion and migration. Nat Rev Cancer 2: 91-100, 2002.

44. Chaijan S, Roytrakul S, Mutirangura A and Leelawat K: Matrigel induces L-plastin expression and promotes L-plastin-dependent invasion in human cholangiocarcinoma cells. Oncol Lett 8: 993-1000, 2014

45. de Araujo VC, Pinto Junior DS, de Sousa SO, Nunes FD and de Araujo NS: Vimentin in oral squamous cell carcinoma. Eur Arch Otorhinolaryngol 250: 105-109, 1993.
46. Mendez MG, Kojima S and Goldman RD: Vimentin induces changes in cell shape, motility, and adhesion during the epithelial to mesenchymal transition. FASEB J 24: 1838-1851, 2010

47. Dal Vechio AM, Giudice FS, Sperandio FF, Mantesso A and Pinto Junior Ddos S: Vimentin expression and the influence of Matrigel in cell lines of head and neck squamous cell carcinoma. Braz Oral Res 25: 235-240, 2011.

48. Price KJ, Tsykin A, Giles KM, Sladic RT, Epis MR, Ganss R, Goodall GJ and Leedman PJ: Matrigel basement membrane matrix influences expression of microRNAs in cancer cell lines. Biochem Biophys Res Commun 427: 343-348, 2012.

49. Ress AL, Stiegelbauer V, Winter E, Schwarzenbacher D, Kiesslich T, Lax S, Jahn S, Deutsch A, Bauernhofer T, Ling $\mathrm{H}$, et al: miR-96-5p influences cellular growth and is associated with poor survival in colorectal cancer patients. Mol Carcinog 54: 1442-1450, 2015.

50. Arndt GM, Dossey L, Cullen LM, Lai A, Druker R, Eisbacher M, Zhang C, Tran N, Fan H, Retzlaff K, et al: Characterization of global microRNA expression reveals oncogenic potential of miR-145 in metastatic colorectal cancer. BMC Cancer 9: 374, 2009.

51. Motoyama K, Inoue H, Takatsuno Y, Tanaka F, Mimori K, Uetake H, Sugihara K and Mori M: Over- and under-expressed microRNAs in human colorectal cancer. Int $\mathrm{J}$ Oncol 34: 1069-1075, 2009.

52. Sarver AL, French AJ, Borralho PM, Thayanithy V, Oberg AL, Silverstein KA, Morlan BW, Riska SM, Boardman LA, Cunningham JM, et al: Human colon cancer profiles show differential microRNA expression depending on mismatch repair status and are characteristic of undifferentiated proliferative states. BMC Cancer 9: 401, 2009.

53. Schepeler T, Reinert JT, Ostenfeld MS, Christensen LL, Silahtaroglu AN, Dyrskjot L, Dyrskjøt L, Wiuf C, Sørensen FJ, Kruhøffer M, et al: Diagnostic and prognostic microRNAs in stage II colon cancer. Cancer Res 68: 6416-6424, 2008.

54. Schetter AJ, Leung SY, Sohn JJ, Zanetti KA, Bowman ED, Yanaihara N, Yuen ST, Chan TL, Kwong DL, Au GK, et al: MicroRNA expression profiles associated with prognosis and therapeutic outcome in colon adenocarcinoma. JAMA 299: 425-436, 2008.

55. Bandrés E, Cubedo E, Agirre X, Malumbres R, Zárate R, Ramirez N, Abajo A, Navarro A, Moreno I, Monzó M and García-Foncillas J: Identification by Real-time PCR of 13 mature microRNAs differentially expressed in colorectal cancer and non-tumoral tissues. Mol Cancer 5: 29, 2006.

56. Kuipers EJ, Grady WM, Lieberman D, Seufferlein T, Sung JJ, Boelens PG, van de Velde CJH and Watanabe T: Colorectal cancer. Nat Rev Dis Primers 1: 15065, 2015. 